Article

\title{
Preparation of Three-Dimensional Photonic Crystals of Zirconia by Electrodeposition in a Colloidal Crystals Template
}

\author{
Lei Pan ${ }^{1}$, Hongbo $\mathrm{Xu}^{1}$, Yunyong Sun ${ }^{2}$, Jiupeng Zhao ${ }^{1, *}$ and $\mathrm{Yao} \mathrm{Li}^{2, *}$ \\ 1 MIIT Key Laboratory of Critical Materials Technology for New Energy Conversion and Storage, \\ School of Chemistry and Chemical Engineering, Harbin Institute of Technology, Harbin 150001, China; \\ Panlei@hit.edu.cn (L.P.); iamxhb@hit.edu.cn (H.X.) \\ 2 Center for Composite Materials and Structures, Harbin Institute of Technology, Harbin 150080, China; \\ sunyunyong1989@126.com \\ * Correspondence: Jiupengzhao@126.com (J.Z.); Yaoli@hit.edu.cn (Y.L.); Tel.: +86-451-8640-3767 (J.Z.); \\ +86-451-8640-2345 (Y.L.)
}

Academic Editor: Qingfeng Yan

Received: 16 June 2016; Accepted: 30 June 2016; Published: 2 July 2016

\begin{abstract}
Three-dimensional photonic crystals of zirconia were prepared by electrodeposition in a colloidal crystals template following calcination at $500{ }^{\circ} \mathrm{C}$. Scanning electron microscopy, thermogravimetric analysis, X-ray diffraction, and reflectance spectroscopy were employed to characterize the photonic crystals of zirconia. It was found that hydrated zirconium ions could penetrate the colloidal crystals template and reach the substrate easily by electrodeposition, which resulted in stronger bonding between the substrate and the as-deposited membrane. Moreover, the electrodeposited membrane had low water content, leading to a low amount of shrinkage during calcination. Both these properties could suppress detachment from the substrate upon removal of the colloidal crystals template. Therefore, the three-dimensional photonic crystals of zirconia synthesized in this study exhibited very good preservation of the ordered structures of the colloidal crystals template with a high density. A peak of reflection higher than $70 \%$ was formed in the reflectance spectrum because of the strong diffraction of the ordered structures.
\end{abstract}

Keywords: zirconia; photonic crystals; colloidal crystals template; electrodeposition

\section{Introduction}

Three-dimensional photonic crystals (3DPCs) are man-made "crystal" structure that consist of two different materials with different dielectric constants arranged in accordance with a certain period in three dimensions. The dielectric constants in 3DPCs are periodic functions in three dimensions. Similar to electron bands existing in a periodic potential field for semiconductor materials, 3DPCs also have photonic bands. The propagation of light of a frequency within the range of the photonic band gap is forbidden in 3DPCs [1,2]. This property is extensively applied in some specialized fields, such as in optical waveguides with high curvature [3,4], optical integrated circuits [4], single-mode luminous diodes [5], low-threshold-value laser communication [1], and paints with tunable structural colors [6], etc. The wide range of promising applications is promoting the rapid development of preparation techniques for 3DPCs.

Among the various preparation methods for 3DPCs, the method based on the use of templates consisting of colloidal crystals is most widely used as a rapid, convenient, and low-cost approach. Capillary forces, as well as electrostatic and other forces, are employed in the self-assembly of mono disperse microspheres on the gas-liquid-solid three-phase boundary to obtain close-packed colloidal crystals (face-centered cubic or opal structures). Subsequently, the voids in the colloidal crystals 
template can be filled by dielectric materials with high refractive index (n) by sol-gel processing, chemical vapor deposition, atomic layer deposition, electrodeposition, or other methods. Finally, the colloidal crystals template is removed to obtain inverse opal structural materials, which are also known as three-dimensional ordered macroporous (3DOM) materials. In comparison with an opal structure, it is easier to form a complete photonic band gap in an inverse opal structure, because this permits the use of a dielectric material with higher $\mathrm{n}$ and lower symmetry. To date, a variety of materials with inverse opal structures, including semi-conductors [7,8], metals [9], metallic oxides [10-13], carbon [14], and polymers [15], have been prepared successfully by using the colloidal crystalstemplating method.

Transition metal oxides are widely used in optical coatings in the visible and near-infrared bands due to their excellent optical properties such as high n, high transmittance, high hardness, good thermostability, and limited thermal expansion. Therefore, transition metal oxides are also ideal alternative materials to prepare inverse opal 3DPCs. Many research groups including ours reported the fabrication of zirconia or yttria-stabilized zirconia (YSZ) with inverse opal structures that were obtained by filling a template of colloidal crystals with a sol or solution of zirconia or YSZ [16-26]. However, no noticeable reflection peak was observed in these reports. The reason may be found in the high water content of zirconia gel that results in a significant amount of shrinkage during the subsequent drying and calcination processes. Excessively intense stress generated by shrinkage destroys the porous structure or even leads to detachment of the membrane. Thus, in these reports the prepared materials were referred to as 3DOMs instead of 3DPCs. The subsequent characterization and application also focused on the properties of the porous materials, including their use for adsorption [21], catalysis [24], and solid fuel cells [22,23]. Clearly, the rapid low-cost preparation of high-quality 3DPCs with transition metal oxides remains a challenge.

The advantage of electrodeposition is that it can be used to fill a colloidal crystals template from bottom to top, leading to higher adhesion and density of the deposited materials than with other methods such as sol-gel and chemical vapor deposition (CVD). Various semi-conductors and metallic photonic crystal materials were fabricated by colloidal crystals template-assisted electrodeposition [8,9]. However, the electrodeposition method of transition metal ions in solution differs from that of simple substances, such as semi-conductors and metals, in that they have no need to undergo a redox reaction on electrodes. Instead, they react with the hydroxyl generated by the electrolysis of water in the vicinity of the electrodes to form a precipitation consisting of hydrous oxides [27]. The latter then undergoes dehydration during the subsequent calcination step and is transformed into a transition metal oxide film. Therefore, the density and adhesion properties of the oxide films may not be as advanced as those of metal and semiconductor films that are generated by the direct redox reaction on electrodes. The properties of deposited oxide film can thus be expected to be closely related to the technological conditions of the electrodeposition process.

In this work, we employed an electrodeposition method to fill the colloidal crystals template to fabricate zirconia 3DPCs with a highly ordered structure. Moreover, the influence of the chosen technological conditions on the morphology and optical properties of the oxide film is characterized and discussed.

\section{Results and Discussion}

\subsection{Electrodeposition of Zirconia}

Identification of the scheme according to which zirconia undergoes electrodeposition is difficult in the case of complex zirconium species that exist in aqueous solutions. However, the process can be safely simplified by two reactions that include:

$$
\begin{gathered}
2 \mathrm{H}_{2} \mathrm{O}+2 \mathrm{e}^{-} \rightarrow \mathrm{H}_{2}+2 \mathrm{OH}^{-} \\
\mathrm{Zr}^{4+}+4 \mathrm{OH}^{-}+\mathrm{xH}_{2} \mathrm{O} \rightarrow \mathrm{Zr}(\mathrm{OH})_{4} \cdot \mathrm{xH}_{2} \mathrm{O} \downarrow
\end{gathered}
$$


As indicated in the above reaction equations, bubbles were observed on the cathodic substrate without the use of a colloidal crystals template when electrodeposition was carried out in a $\mathrm{ZrOCl}_{2}$ solution. Thus, the use of the substrate in combination with the colloidal crystals template for electrodeposition would cause entrapment of the bubbles in the template, which would be detrimental to the ordered structure and adhesion of the deposited membrane to the substrate. In order to restrain the generation of $\mathrm{H}_{2}, \mathrm{H}_{2} \mathrm{O}_{2}$ was introduced into the electrolyte. In the presence of $\mathrm{H}_{2} \mathrm{O}_{2}$, the formation of gas was no longer observed on the cathodic substrate. In this case, $\mathrm{OH}^{-}$is expected to be produced via the following reaction [27]:

$$
\mathrm{H}_{2} \mathrm{O}_{2}+2 \mathrm{e}^{-} \rightarrow 2 \mathrm{OH}^{-}
$$

A layer of sufficient thickness of deposited zirconia is necessary to form an obvious diffraction effect. However, the poor electrical conductivity of the deposited hydrous zirconia causes the applied voltage to increase with time. In our work, once the applied voltage reached the protective value, which was set as $5 \mathrm{~V}$, the current decreased rapidly. At this stage the maximum thickness of the zirconia membrane electrodeposited from the $\mathrm{ZrOCl}_{2} / \mathrm{H}_{2} \mathrm{O}_{2}$ solution was still insufficient to form noticeable structure coloration. Hence, $\mathrm{NaHCO}_{3}$ was added to the electrolyte to adjust the $\mathrm{pH}$ to the isoelectric point of the zirconium ionic groups, thereby accelerating the process of electrodeposition dramatically. The result will be discussed in a subsequent section.

\subsection{Thermogravimetric (TG) Analysis}

The thermogravimetric analysis curve for the electrodeposited zirconia membrane after drying is shown in Figure 1. It can be observed that the majority of weight loss, 37.3\% in total, took place before $500{ }^{\circ} \mathrm{C}$. This result is similar to the electrodeposition of YSZ under similar conditions [28] and the observed weight loss is far lower than in the sol-gel method (65.4\%) [16]. Lower weight loss is considered beneficial to preserve the structure of the colloidal crystals template and maintain the optical properties of 3DPCs. Above $500{ }^{\circ} \mathrm{C}$ up to $800{ }^{\circ} \mathrm{C}$, the registered weight loss is only $0.6 \%$. Furthermore, $500{ }^{\circ} \mathrm{C}$ was also found to be sufficiently high to remove the polystyrene (PS) template. Calcination at higher temperatures was found to bring about a series of destructive effects, including thermal expansion differences between the zirconia membrane and the substrate, softening of the substrate, and destruction of the indium tin oxides (ITO) layer. Therefore, heat treatments were conducted at $500^{\circ} \mathrm{C}$ in the subsequent experiment.

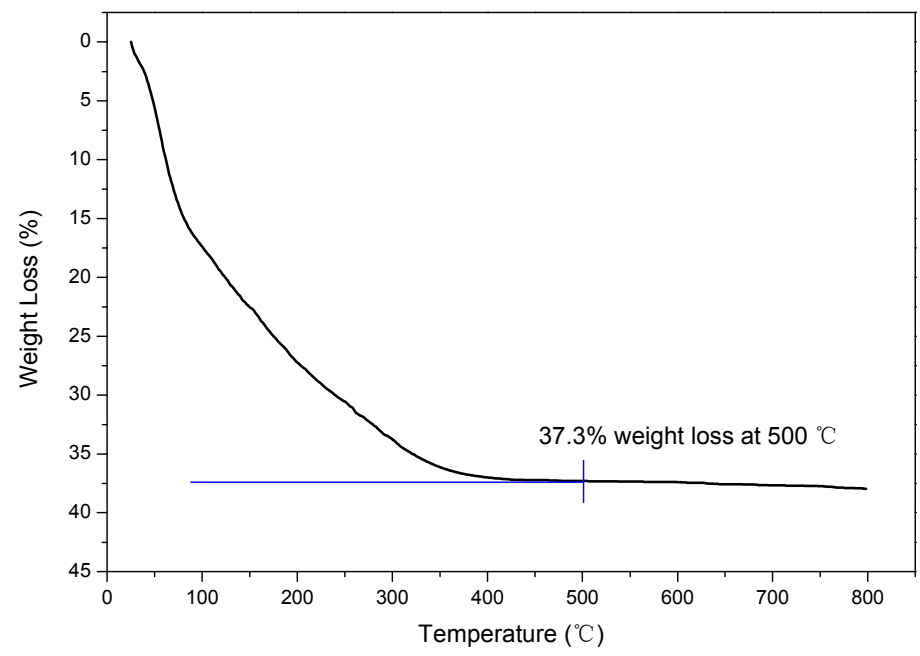

Figure 1. Thermogravimetric (TG) curves of the hydrous $\mathrm{ZrO}_{2}$ membrane. 


\subsection{X-Ray Diffraction(XRD) Analysis}

The XRD patterns of the deposited membrane before and after calcination are shown in Figure 2. The sample before calcination exhibits two broad peaks at $30^{\circ}$ and $55^{\circ}$. This pattern should be regarded as being representative of amorphous zirconium hydroxide [29]. After calcination at $500{ }^{\circ} \mathrm{C}$, the sharp peaks that appeared in the XRD pattern correspond very well with the monoclinic phase of zirconia (JCPDS card No. 37-1484), indicating that crystallization had been accomplished.

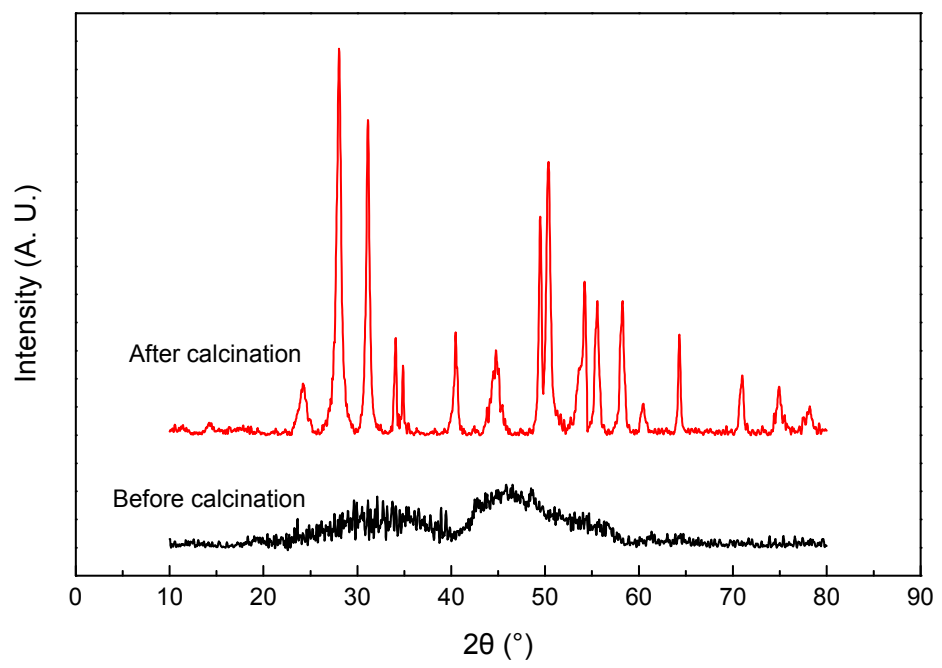

Figure 2. X-ray diffraction (XRD) patterns for deposited membrane before and after calcination.

\subsection{The Microstructure Analysis of Photonic Crystal Layer}

The scanning electron microscopy (SEM) image in Figure 2a shows the morphology of as-deposited hydrous zirconia in the colloidal crystals template. This figure indicates that regulation of the electrodeposition conditions enables a thick hydrous zirconia membrane to be obtained. The sediment has reached the top layer of the colloidal crystals template. Although small holes can be observed on the surface of the sediment, suggesting shrinkage during the drying process, the entire membrane is maintained in a continuous and complete state. The morphologies of zirconia 3DOM after calcination at $500{ }^{\circ} \mathrm{C}$ are shown in Figure $2 b-d$. It can be observed from Figure $2 b$ that the zirconia membrane is able to retain a complete inverse opal structure within a scale of about $10 \mu \mathrm{m}$, whereas on a larger scale, cracks resulting from shrinkage during calcination can be found, though they are at an acceptable level, as shown in Figure 2c. The shrinkage of the structure may be restricted in the two dimensionalities parallel to the substrate due to the high adhesion but still may happen vertically. The latter may lead to a blue shift of the reflective peak. The relatively limited shrinkage may be the consequence of the relatively lower water and organic substance content, as compared to the sol-gel method [16]. In addition, no severe detachment of the zirconia membrane is found. In the lower parts of the cracks, fragments of zirconia 3DOM are still tightly attached to the substrate (Figure 3d), indicating that hydrated zirconium ions were able to penetrate the colloidal crystals template easily and that the zirconia membrane grew in a bottom-up manner by starting from the substrate. This fact, along with the small amount of detachment, clearly proves the strong binding force between the zirconia membrane and the substrate. Besides, Figure $2 \mathrm{~d}$ also shows that an inverse opal structure exceeding 10 layers was obtained by regulating the technological conditions under which electrodeposition was carried out. A certain number of structural periods would ensure the generation of multiple Bragg diffractions. 

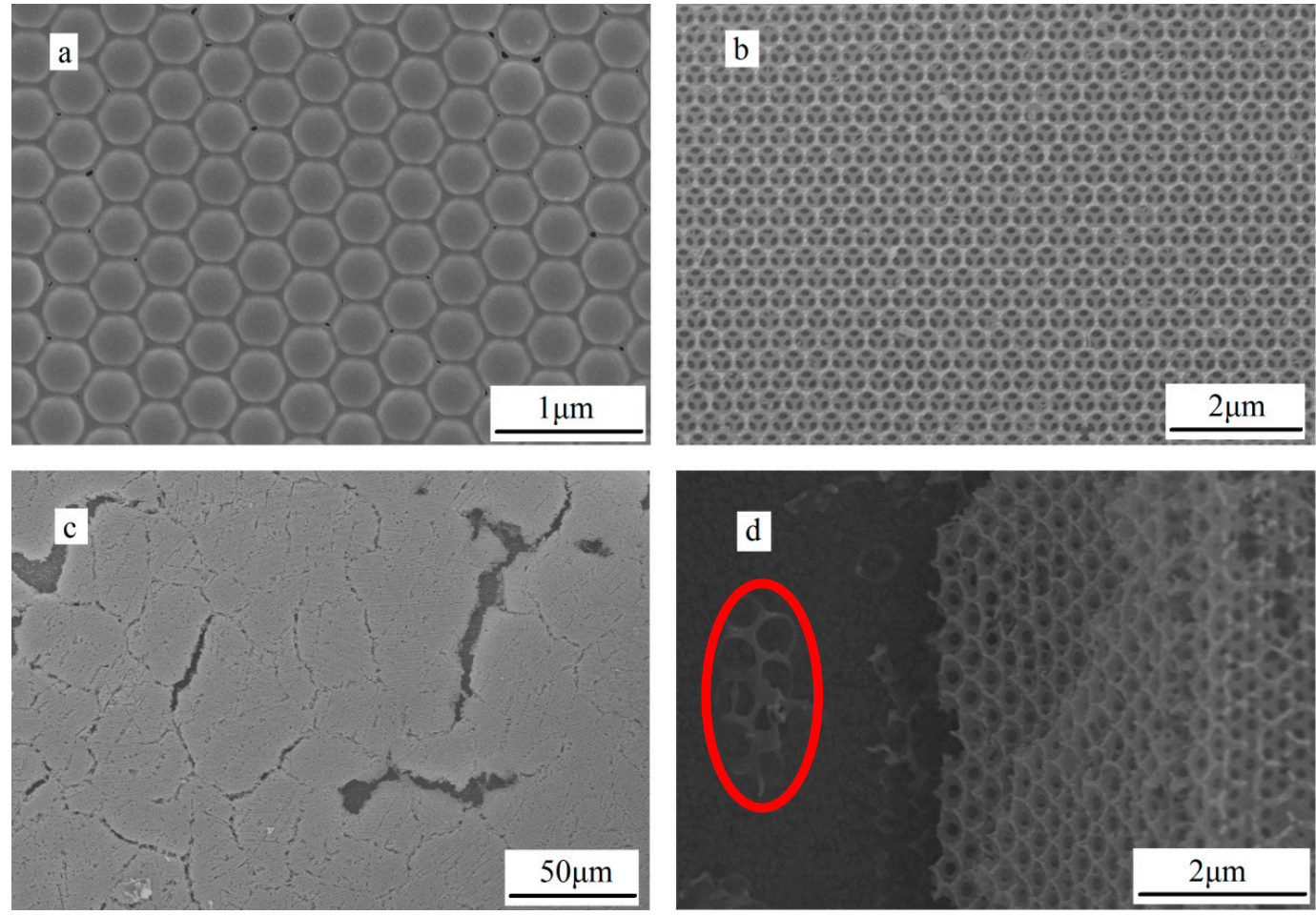

Figure 3. Scanning electron microscopy (SEM) images for (a) Polystyrene/hydrous $\mathrm{ZrO}_{2} 3 \mathrm{DPCs}$; (b-d) $\mathrm{ZrO}_{2}$ 3DPCs.

\subsection{Spectral Analysis of Zirconia 3DPCs}

A simple way to predict the reflective peak position $(\lambda)$ of 3DPCs with an opal or inverse opal structure is to use the Bragg-Snell equation [30]:

$$
\lambda=2 \sqrt{2 / 3} D \sqrt{n_{e f f}^{2}-\sin ^{2} \theta}
$$

where $D$ is the diameter of the microspheres ( $391 \mathrm{~nm}$ for this study), and $\theta$ is the incident angle $\left(0^{\circ}\right.$ for this study). Further, $n_{\text {eff }}$ is the effective refractive index of 3DPCs and can be expressed as:

$$
n_{e f f}=\sqrt{n_{a}^{2} f+n_{b}^{2}(1-\mathrm{f})}
$$

where $n_{a}$ and $n_{b}$ are the $n$ of two different dielectric media constituting the 3DPCs and $f$ is the volume proportion of dielectric media $a$. In the ideal opal structure, $n_{a}$, the $n$ of PS, is 1.59 and $f$ should be 0.746 . Thus, the reflective peak of PS 3DPCs in this study should be located at $934 \mathrm{~nm}$. In the case of the zirconia inverse opal structure, media $a$ is replaced by air and the $n_{a}$ should be 1 . Media $b$ is replaced by electrodeposited zirconia and the $n_{b}$ should be 2.1 if the electrodeposited zirconia has the same density as bulk zirconia. If the electrodeposited zirconia membrane precisely replicates the structure of the colloidal template, it can be calculated that the reflective peak of zirconia3DPCs should be located at $872 \mathrm{~nm}$. The experimental reflective spectra of PS and zirconia 3DPCs are given in Figure 4. A reflective peak near 95\% can be found for PS 3DPCs in Figure 4, whose location is in very good agreement with the predicted value, indicating the highly ordered structure of the PS 3DPCs. However, the reflective peak for zirconia 3DPCs shows a noteworthy blue shift compared with the calculated value (about $230 \mathrm{~nm}$ ). The main reason for the blue shift may be that the actual refractive index of electrodeposited zirconia is lower than the refractive index of bulk zirconia because of its lower density derived from dehydration during calcination. However, compared with the reflective peak width of the original template, the reflective peak width of zirconia 3DPCs is expanded slightly. Therefore, 
the actual refractive index of electrodeposited zirconia remains higher than the refractive index of PS. The shrinkage of the structure, especially in the vertical direction, along with the volume proportion of zirconia which is lower than the ideal value, may also contribute to the blue shift. Moreover, in comparison with the reflective peak of the colloidal crystals template, the intensity of the reflective peak of zirconia 3DPCs is reduced because of the cracks (see Figure 3c), although to an acceptable extent (higher than $70 \%$ ), indicating that the orderliness of the template is adequately preserved.

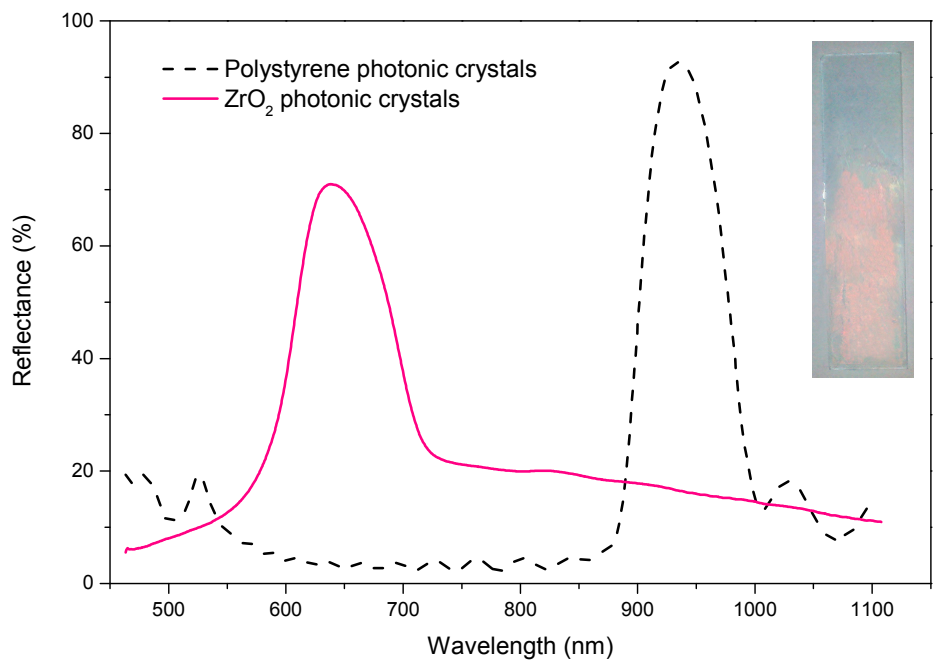

Figure 4. Reflectance spectra for polystyrene and $\mathrm{ZrO}_{2} 3 \mathrm{DPCs}$ and the visual appearance of $\mathrm{ZrO}_{2}$ 3DPCs (insert).

In summary, zirconia 3DPCs are able to maintain the ordered structure of the original template; hence, strong multiple Bragg diffractions are generated, thereby apparently resulting in a salmon-colored structure (see Figure 4 insert).

\section{Materials and Methods}

All reagents except the water used were purchased from Sigma-Aldrich without further purification. High-purity water with a resistivity of $18.2 \mathrm{M} \Omega \cdot \mathrm{cm}$ at $25^{\circ} \mathrm{C}$ was prepared by using a water purification system (CSR-1-30T). Monodisperse polystyrene (PS) microspheres with an average diameter of $391 \mathrm{~nm}$ were synthesized by an emulsifier-free emulsion polymerization technique [31]. The polydispersity index (PDI) of diameter was 1.04 .

The cathodic electrodeposition of zirconia was performed with a CHI-660D electrochemical workstation. Indium-doped tin oxide glass slides (ITO, $1 \times 5 \mathrm{~cm}, \sim 9 \Omega$ ) were used as cathodic substrates. In the fabrication of inverse opal zirconia, PS colloidal crystal templates were grown on the ITO in advance by vertical deposition $[9,16]$. A rectangular $\mathrm{Pt}(1 \times 5 \mathrm{~cm})$ electrode was used as counter electrode.

First, an aqueous solution containing $0.2 \mathrm{M} \mathrm{ZrOCl}_{2}$ and $0.24 \mathrm{M} \mathrm{H}_{2} \mathrm{O}_{2}$ was prepared, to which an aqueous solution of $0.1 \mathrm{M} \mathrm{NaHCO}_{3}$ was added drop by drop until a small amount of sedimentation was generated. The precipitationwould dissolve after vibration. Then the solution was diluted untilthe concentration of $\mathrm{ZrOCl}_{2}$ was $0.1 \mathrm{M}$. Galvanostatic electrodeposition was carried out with a current density of $1 \mathrm{~mA} / \mathrm{cm}^{2}$ in an ice/water bath. The as-deposited films were dried for $24 \mathrm{~h}$ at $80{ }^{\circ} \mathrm{C}$, followed by calcination for $1 \mathrm{~h}$ at $500^{\circ} \mathrm{C}$ to remove the PS template.

SEM images were obtained using a Hitachi SU 8010 microscope operated at $15 \mathrm{kV}$. The average diameter of the PS microspheres was calculated from more than 100 microspheres. PDI $=D_{m} / D_{n-1}$, where $D_{m}$ and $D_{n}$ were the weight-average and number-average diameters, respectively [32]. The normal-incident reflectance spectra of 3DPCswere obtained by using an Ocean Optics Maya 2000-Pro 
instrument equipped with a reflection probe. A specular reflectance standard (PN A338-MS-1)with a reflectance of $85 \%-90 \%$ was used as measured reference. The thermogravimetric analysis was performed using an STA 8000 device at a scan rate of $10^{\circ} \mathrm{C} / \mathrm{min}$ with a $25 \mathrm{~mL} / \mathrm{min}$ flow of nitrogen of $99.99 \%$ purity. The crystalline structures of the membrane were analyzed by using a D/Max-rB X-ray diffractometer $\left(\mathrm{Cu} \mathrm{K} \mathrm{K}_{\alpha}\right.$ radiation) at a scan rate of $5^{\circ} / \mathrm{min}$.

\section{Conclusions}

In this study, zirconia 3DPCs with a continuous ordered structure in a large area were obtained by an electrodeposition method. PS colloidal crystals on ITO glass were used as sacrificial templates and an aqueous solution of $\mathrm{ZrOCl}_{2}$ was used as an electrolyte, to which $\mathrm{H}_{2} \mathrm{O}_{2}$ was added to restrain the generationof hydrogen and to which $\mathrm{NaHCO}_{3}$ solution was added to regulate the $\mathrm{pH}$ to increase the thickness of the deposited membrane. Calcination at $500{ }^{\circ} \mathrm{C}$ was employed to remove the template and water. The zirconia 3DPCs fabricated by electrodeposition had relatively high density and strong adhesion, with very good preservation of the orderliness of the colloidal crystals template, resulting in an obvious reflective peak and structural color. The high quality of the electrodeposited zirconia 3DPCs may be attributable to the following: the low water content in electrodeposited hydrous zirconia with a consequent low weight loss during calcination, together with a bottom-up deposition mode that ensures bonding between the deposited member and the substrate and a comparatively low degree of detachment.

Most of the above conclusions may also be valid for multiple other metallic oxides. Therefore, this study has provided a new approach to prepare high-quality inverse opal 3DPCs with metallic oxides.

Acknowledgments: We thank the National Natural Science Foundation of China (No.51572058, 91216123, 51174063, 51502057), the Heilongjiang Postdoctoral Fund (No. LBH-Z15078), the Aerospace support fund (NO. JZ20150048), the Natural Science Foundation of Heilongjiang Province (E201436), the International Science \& Technology Cooperation Program of China (2013DFR10630, 2015DFE52770) and the Specialized Research Fund for the Doctoral Program of Higher Education (SRFDP 20132302110031).

Author Contributions: Jiupeng Zhao and Yao Li conceived the research plan, Yunyong Sun performed the experiments, Hongbo Xu analyzed the data and Lei Pan wrote the paper.

Conflicts of Interest: The authors declare no conflict of interest.

\section{References}

1. Yablonovitch, E. Inhibited spontaneous emission in solid-state physics and electronics. Phys. Rev. Lett. 1987, 58, 2059-2062. [CrossRef] [PubMed]

2. John, S. Strong localization of photons in certain disordered dielectric superlattices. Phys. Rev. Lett. 1987, 58, 2486-2489. [CrossRef] [PubMed]

3. Mekis, A.; Chen, J.C.; Kurland, I.; Fan, S.H.; Villeneuve, P.R.; Joannopoulos, J.D. High transmission through sharp bends in photonic crystal waveguides. Phys. Rev. Lett. 1996, 77, 3787-3790. [CrossRef] [PubMed]

4. Lin, S.Y.; Chow, E.; Hietala, V.; Villeneuve, P.R.; Joannopoulos, J.D. Experimental demonstration of guiding and bending of electromagnetic waves in a photonic crystal. Science 1998, 282, 274-276. [CrossRef] [PubMed]

5. Yablonovitch, E. Photonic band-gap structures. J. Opt. Soc. Am. B: Opt. Phys. 1993, 10, 283-295. [CrossRef]

6. Lai, C.-F.; Wang, Y.-C. Colloidal photonic crystals containing silver nanoparticles with tunable structural colors. Crystals 2016, 6, 61. [CrossRef]

7. Blanco, A.; Chomski, E.; Grabtchak, S.; Ibisate, M.; John, S.; Leonard, S.W.; Lopez, C.; Meseguer, F.; Miguez, H.; Mondia, J.P.; et al. Large-scale synthesis of a silicon photonic crystal with a complete three-dimensional bandgap near 1.5 micrometres. Nature 2000, 405, 437-440. [PubMed]

8. Meng, X.; Al-Salman, R.; Zhao, J.; Borissenko, N.; Li, Y.; Endres, F. Electrodeposition of 3D ordered macroporous germanium from ionic liquids: A feasible method to make photonic crystals with a high dielectric constant. Angew. Chem. Int. Ed. 2009, 48, 2703-2707. [CrossRef] [PubMed]

9. Li, Z.; Yang, L.; Ge, D.; Ding, Y.; Pan, L.; Zhao, J.; Li, Y. Magnetron sputtering sic films on nickel photonic crystals with high emissivity for high temperature applications. Appl. Surf. Sci. 2012, 259, 811-815. [CrossRef] 
10. Xin, W.; Zhao, J.; Ding, Y.; Li, Y. Fabrication of three-dimensionally ordered macroporous $\mathrm{Ta}_{2} \mathrm{O}_{5}$ films through aqueous organic gel process. Appl. Surf. Sci. 2011, 257, 10725-10728.

11. Huang, K.M.; Ho, C.L.; Chang, H.J.; Wu, M.C. Fabrication of inverted zinc oxide photonic crystal using sol-gel solution by spin coating method. Nanoscale Res. Lett. 2013, 8. [CrossRef] [PubMed]

12. Tong, Z.; Hao, J.; Zhang, K.; Zhao, J.; Su, B.-L.; Li, Y. Improved electrochromic performance and lithium diffusion coefficient in three-dimensionally ordered macroporous $\mathrm{V}_{2} \mathrm{O}_{5}$ films. J. Mater. Chem. C 2014, 2, 3651-3658. [CrossRef]

13. Kapitonov, A.M.; Gaponenko, N.V.; Bogomolov, V.N.; Prokofiev, A.V.; Samoilovich, S.M.; Gaponenko, S.V. $\mathrm{SiO}_{2} / \mathrm{TiO}_{2}$ submicron 3D lattice: A new step towards visible-range photonic crystals. Nanoscale Res. Lett. 1997, 54-57. [CrossRef]

14. Zakhidov, A.A.; Baughman, R.H.; Iqbal, Z.; Cui, C.X.; Khayrullin, I.; Dantas, S.O.; Marti, I.; Ralchenko, V.G. Carbon structures with three-dimensional periodicity at optical wavelengths. Science 1998, 282, 897-901. [CrossRef] [PubMed]

15. Ge, D.; Yang, L.; Tong, Z.; Ding, Y.; Xin, W.; Zhao, J.; Li, Y. Ion diffusion and optical switching performance of $3 \mathrm{D}$ ordered nanostructured polyaniline films for advanced electrochemical/electrochromic devices. Electrochim. Acta 2013, 104, 191-197. [CrossRef]

16. Zhao, J.P.; Li, Y.; Xin, W.H.; Li, X. Preparation and characterization of three-dimensionally ordered macroporous yttria-stabilized zirconia by aqueous organic gel route. J. Solid State Chem. 2008, 181, 239-244. [CrossRef]

17. Lashtabeg, A.; Drennan, J.; Knibbe, R.; Bradley, J.L.; Lu, G.Q. Synthesis and characterisation of macroporous yttria stabilised zirconia (YSZ) using polystyrene spheres as templates. Microporous Mesoporous Mater. 2009, 117, 395-401. [CrossRef]

18. Lashtabeg, A.; Bradley, J.L.; Vives, G.; Drennan, J. The effects of templating synthesis procedures on the microstructure of yttria stabilised zirconia (YSZ) and NiO/YSZ templated thin films. Ceram. Int. 2010, 36, 653-659. [CrossRef]

19. Xiaolong, X.; Hui, Z.; Shengnan, L.; Fan, L.; Jinxiu, W. Preparation of three-dimensional ordered macroporous zirconia and characteristics of its pore walls. J. Chin. Ceram. Soc. 2013, 36, 705-709.

20. Shen, Y.; Wu, Q.Z.; Li, Y.G. Three dimensional ordered macroporous $\mathrm{ZrO}_{2}$ prepared by directly calcining $\mathrm{ZrOCl}_{2}$. Acta. Phys. Chim. Sin. 2006, 22, 1121-1125.

21. Davis, M.; Ramirez, D.A.; Hope-Weeks, L.J. Formation of three-dimensional ordered hierarchically porous metal oxides via a hybridized epoxide assisted/colloidal crystal templating approach. ACS Appl. Mater. Interfaces 2013, 5, 7786-7792. [CrossRef] [PubMed]

22. Zhang, N.; Li, J.; Li, W.; Ni, D.; Sun, K. High performance three-dimensionally ordered macroporous composite cathodes for intermediate temperature solid oxide fuel cells. Rsc Adv. 2012, 2, 802-804. [CrossRef]

23. Liang, B.; Suzuki, T.; Hamamoto, K.; Yamaguchi, T.; Sumi, H.; Fujishiro, Y.; Ingram, B.J.; Carter, J.D. A reduced temperature solid oxide fuel cell with three-dimensionally ordered macroporous cathode. J. Power Sources 2012, 212, 86-92. [CrossRef]

24. Zhang, X.; Su, H.; Yang, X. Catalytic performance of a three-dimensionally ordered macroporous $\mathrm{Co} / \mathrm{ZrO} 2$ catalyst in fischer-tropsch synthesis. J. Mol. Catal. A Chem. 2012, 360, 16-25. [CrossRef]

25. Misawa, H.; Nishijima, Y.; Ueno, K.; Juodkazis, S.; Mizeikis, V.; Maeda, M.; Minaki, M. Tunable single-mode photonic lasing from zirconia inverse opal photonic crystals. Opt. Express 2008, 16, 13676-13684. [CrossRef] [PubMed]

26. Schroden, R.C.; Al-Daous, M.; Blanford, C.F.; Stein, A. Optical properties of inverse opal photonic crystals. Chem. Mater. 2002, 14, 3305-3315. [CrossRef]

27. Zhitomirsky, I. Cathodic electrodeposition of ceramic and organoceramic materials. Fundamental aspects. Adv. Colloid Interface Sci. 2002, 97, 279-317. [CrossRef]

28. Zhigang, X.; Tameru, S.; Sankar, J. Synthesis of yttria stabilized zirconia thin films by electrolytic deposition. Ceram. Eng. Sci. Proc. 2004, 25, 339-344.

29. Aghazadeh, M. Cathodic electrodeposition of $\mathrm{ZrO}_{2}$ : Impact of current density on the crystal structure, composition and morphology. J. Electrochem. Soc. 2012, 159, E53-E58. [CrossRef]

30. Allard, M.; Sargent, E.H.; Kumacheva, E.; Kalinina, O. Characterization of internal order of colloidal crystals by optical diffraction. Opt. Quant. Electron. 2002, 34, 27-36. [CrossRef] 
31. Wang, H.; Zhang, S.; Wang, M.Z.; Ge, X.W. Preparation of monodisperse polystyrene particles from emulsifier-free miniemulsion polymerization. Chem. Lett. 2008, 37, 1158-1159. [CrossRef]

32. Pan, L.; Wang, Y.; Xu, H.; Ding, Y.; Li, Y.; Zhao, J. Synthesis of silica particles with precisely tailored diameter. Chin. J. Chem.Phys. 2014, 27, 563-567. [CrossRef]

(C) 2016 by the authors; licensee MDPI, Basel, Switzerland. This article is an open access article distributed under the terms and conditions of the Creative Commons Attribution (CC-BY) license (http:/ / creativecommons.org/licenses/by/4.0/). 